\title{
"ANALISIS REALISASI ANGGARAN BIAYA BAHAN BAKU PROYEK REHAB GEDUNG PLN TENGGARONG TAHUN 2015 PADA CV. RAJAWALI ADI PUTRA"
}

\author{
Rudy Syafariansyah \\ (Fakultas Ekonomi, Universitas Widya Gama Mahakam) \\ Jl. KH. Wahid Hasyim, Sempaja, Samarinda, Kalimantan Timur, Indonesia \\ Telp : (0541) 734294-737222, Fax : (0541) 736572 \\ rudysyafariansyah@uwgm.ac.id
}

\begin{abstract}
Abstrak
Analisis Realisasi Anggaran Biaya Bahan Baku Proyek Rehab Gedung PLN Tenggarong Tahun 2015 pada CV. Rajawali Adi Putra, dengan Tujuan penelitian ini adalah untuk mengetahui selisih antara rencana dengan realisasi anggaran biaya bahan baku proyek rehab gedung PLN Tenggarong tahun 2015 pada CV. Rajawali Adi Putra. Metode penelitian ini menggunakan studi komparatif atau perbandingan dengan alat analisis dalam bentuk tabel dengan perkalian volume dan harga satuan pekerjaan untuk menghitung selisih antara rencana dan realisasi anggaran biaya. Dari hasil analisis, diketahui bahwa terdapat selisih antara rencana dengan realisasi anggaran biaya bahan baku proyek rehab gedung PLN Tenggarong tahun 2015 pada CV. Rajawali Adi Putra sebesar Rp. 3.255.000,- (tiga juta dua ratus lima puluh lima ribu rupiah) atau 2,76\%, yang berarti rencana lebih besar dari realisasi anggaran biaya bahan baku. Dengan demikian hipotesis yang diajukan dapat diterima.
\end{abstract}

Keyword: Studi Komparatif, Anggara Biaya

\section{PENDAHULUAN}

Suatu proyek pembangunan dapat memerlukan perencanaan yang matang, pelaksanaan yang teliti serta pemanfaatan suatu proyek agar dapat sesuai dengan kebutuhan yang ada. Pengelolaan proyek meliputi perencanaan, pelaksanaan, pengawasan dan monitoring atas elemen proyek seperti sumber daya (bahan, peralatan, dan manusia), waktu serta mutu proyek yang dihasilkannya.

Manajemen proyek selalu diungkapkan bahwa suatu proyek dalam pelaksanaannya harus memenuhi 3 (tiga) kriteria, yaitu biaya proyek, mutu pekerjaan dan waktu menyelesaikan pekerjaan. Akan tetapi yang paling utama

adalah biaya proyek. Jika biaya proyek mencukupi maka kegiatan proyek dari awal hingga akhir proyek akan berjalan lancar. Namun sebaliknya apabila biaya tersebut kurang maka akan terjadi banyak hambatan untuk menjalani proyek tersebut. Oleh karena itu perlu diadakan manajemen proyek untuk mengkoordinasi dan mengendalikan kegiatan proyek yang semakin kompleks, guna memungkinkan melakukan pemilihan rencana kerja yang berdampak baik terhadap laba.

Dalam sebuah proyek pembangunan baik itu rehabilitas bangunan maupun penambahan fasilitas pastinya diawali dengan proses penentuan tujuan, kemudian diikuti oleh proses perencanaan untuk pencapaian tujuan tersebut. Pada proses perencanaan yang menjadi salah satu tujuan utama dalam melaksanakan pembangunan proyek adalah merencanakan penyusunan peta dari seluruh kegiatan proyek. Peta tersebut merangkai semua pekerjaan dan tugas, beserta sumber dayanya untuk mencapai tujuan proyek yang telah disepakati. Perencanaan harus dilakukan dengan baik karena fungsi dari perencanaan itu sendiri adalah meletakkan dasar sasaran proyek yaitu 
jadwal, anggaran dan mutu. Untuk mendapatkan hasil keuntungan yang maksimal dari pelaksanaan pembangunan proyek yang akan dilakukan. Dalam hal ini sangat penting adanya pengelolaan manajemen yang baik khususnya yang berkaitan dengan anggaran biaya, sehingga perlu dibuat sebuah rencana anggaran biaya proyek yang efisien dan dapat dipertanggungjawabkan.

Anggaran yang paling sering dalam sebuah proyek baik proyek pembangunan maupun rehabilitasi adalah anggaran biaya operasional, yaitu anggaran biaya bahan baku dan biaya tenaga kerja. Namun yang sering dilakukan oleh perusahaan kontraktor adalah menetapkan biaya bahan baku sebelum menetapkan biaya tenaga kerja, karena biaya bahan baku tidak bisa dilakukan dengan hanya mengira suatu harga, namun biaya atau harga bahan baku diperlukan survey terlebih dahulu sebelum dilakukan penetapan yang akan diajukan sebagai harga penawaran proyek. Selain itu biaya bahan baku juga selalu berubah-ubah dalam kurun

\section{METODOLOGI PENELITIAN}

Penelitian ini merupakan studi kasus CV. Rajawali Adi Putra di Samarinda. Metode yang digunakan adalah studi komparatif atau perbandingan antara rencana dengan realisasi anggaran biaya bahan baku pada proyek yang telah dikerjakan CV. Rajawali Adi Putra.

\section{Variabel}

Sesuai dengan identifikasi variabel penelitian, maka definisi operasional dapat dijelaskan sebagai berikut :

1. Anggaran biaya bahan baku adalah merupakan anggaran yang digunakan dalam pembelian bahan baku yang akan digunakan oleh perusahaan.

2. Rencana anggaran biaya merupakan perencanaan keuangan yang dibuat secara terperinci tentang banyaknya kebutuhan material bahan yang akan digunakan oleh perusahaan. Sedangkan rencana anggaran biaya (RAB) yang waktu yang tidak menentu, hal ini juga harus menjadi perhatian oleh para pelaku perusahaan kontraktor, agar tidak mengalami kerugian setelah diberlakukannya harga penawaran proyek.

Sebagaimana pada perusahaan CV. RAJAWALI ADI PUTRA yang berlokasi di Jl. Sultan Sulaiman Rt. 12 No. 29, Samarinda, perusahaan ini bergerak dalam kegiatan usaha proyek pembangunan rumah, desain dan segala macam bentuk renovasi, yang juga melaksanakan proses penyusunan anggaran, layaknya sebagai suatu proyek pembangunan rumah, desain dan renovasi, perusahaan ini juga membuat perencanaan biaya dalam penyusunan anggaran biaya proyek pembangunan rumah, desain dan renovasi. Sehingga penulis merumuskan masalah yaitu " Apakah terdapat selisih antara rencana dengan realisasi anggaran biaya bahan baku dalam proyek Rehab gedung PLN Tenggarong tahun 2015 pada CV. RAJAWALI ADI PUTRA"?

digunakan oleh pemimpin CV Rajawali Adi Putra di Samarinda digunakan sebagai acuan untuk mengetahui besar anggaran dalam sebuah proyek.

3. Rekapitulasi rencana anggaran biaya dibuat dan digunakan untuk mengetahui jumlah harga dan kegiatan proyek yang akan dikerjakan, ini memuat jumlah anggaran yang dibutuhkan dalam sebuah proyek.

4. Realisasi anggaran biaya adalah sebuah anggaran yang telah digunakan atau dana yang telah terpakai dalam sebuah kegiatan pembangunan atau proyek.

5. Rekapitulasi anggaran biaya merupakan jumlah harga aktual dari kegiatan proyek yang telah dikerjakan.

\section{Rincian data yang diperlukan}

Sesuai dengan tujuan analisis, maka data-data yang peneliti pergunakan dalam 
mendukung pemecahan masalah nantinya adalah:

1. Data primer adalah data utama yang diperlukan peneliti dan akan digunakan sebagai bahan penelitian meliputi :

a. Data rencana anggaran biaya yang terdiri dari harga satuan, harga analisa, rencana anggaran biaya, dan rekapitulasi biaya.

b. Data realisasi anggaran biaya.

\section{Teknik Pengumpulan Data}

\section{Adapun teknik}

pengumpulandata yang diperlukan sehubungan dengan penelitian ini, maka teknik pengumpulan data yang dilakukan dengan cara:

1. Penelitian Dokumenter

$$
\text { Yaitu meneliti dan }
$$
mempelajari literatur-literatur yang ada kaitannya dengan manajemen

\section{Metode Analisis}

Alat analisis yang digunakan untuk menganalisis permasalahan perhitungan rencana dan realisasi anggaran biaya dalam perusahaan ini, peneliti menggunakan perhitungan rencana anggaran biaya menurut Wulfram I. Ervianto, yang dibuat dalam bentuk tabel yang terdiri dari tiga lajur anggaran biaya serta buku-buku ilmiah lainnya yang sehubungan dengan penelitian yang dilakukan.

2. Studi Lapangan

Yaitu pengumpulan data langsung dari lapangan. Ada dua cara dalam pengumpulan data ini yaitu:

a. Teknik observasi, teknik ini digunakan untuk mendapatkan atau memperoleh data yang lebih nyata dengan cara melakukan survey dilapangan dengan maksud mendapatkan data yang lebih komplit.

b. Teknik wawancara, yaitu teknik pengumpulan data yang dilakukan dengan mengadakan wawancara secara langsung dengan pemimpin perusahaan.

kolom yaitu kolom uraian pekerjaan, kolom volume dan kolom harga satuan pekerjaan, selanjutnya. perhitungan rencana anggaran biaya didapat dari penjumlahan perkalian volume dan harga satuan pekerjaan. Selanjutnya menghitung keseluruhan atau rekapitulasi sesuai dengan kegiatan pekerjaan.

Tabel. 1 Perhitungan Rencana Anggaran Biaya

\begin{tabular}{|l|l|l|l|l|l|}
\hline No & Uraian Pekerjaan & Sat & Vol & Harga Satuan & Jumlah Harga \\
\hline $\mathrm{X} \mathrm{X}$ & $\mathrm{XX}$ & $\mathrm{XX}$ & $\mathrm{XX}$ & $\mathrm{XX}$ & $\mathrm{XX}$ \\
\hline & & & & Jumlah & $\mathrm{XX}$ \\
\hline
\end{tabular}

Sumber: (Wulfram I. Ervianto)

Tabel. 2 Rekapitulasi Rencana Anggaran Biaya

Proyek :

Lokasi :

\begin{tabular}{|c|l|l|}
\hline No. & \multicolumn{1}{|c|}{ Uraian Pekerjaan } & \multicolumn{1}{c|}{ Jumlah Harga (Rp) } \\
\hline $\mathrm{XX}$ & $\mathrm{XX}$ & $\mathrm{XX}$ \\
\hline & & \\
\hline & Jumlah & $\mathrm{XX}$ \\
\hline & Dibulatkan & $\mathrm{XX}$ \\
\hline & Terbilang: & \\
\hline
\end{tabular}

Sumber: (Wulfram I. Ervianto) 
Tabel. 3 Realisasi Anggaran Biaya

\begin{tabular}{|l|l|l|l|l|l|}
\hline \multicolumn{1}{|c|}{ No. } & Uraian Pekerjaan & Sat & Vol & Harga Satuan & Jumlah \\
\hline $\mathrm{X}$ & & & & & \\
$\mathrm{X}$ & $\mathrm{XX}$ & $\mathrm{XX}$ & $\mathrm{XX}$ & $\mathrm{XX}$ & $\mathrm{XX}$ \\
\hline & & & & Jumlah & $\mathrm{XX}$ \\
\hline
\end{tabular}

Sumber : Data Diolah

Tabel. 4 Rekapitulasi Realisasi Anggaran Biaya

Proyek :

Lokasi :

\begin{tabular}{|c|l|l|}
\hline No. & \multicolumn{1}{|c|}{ Uraian Pekerjaan } & \multicolumn{1}{|c|}{ Jumlah Harga (Rp) } \\
\hline $\mathrm{XX}$ & $\mathrm{XX}$ & $\mathrm{XX}$ \\
\hline & & \\
\hline & Jumlah & $\mathrm{XX}$ \\
\hline & Dibulatkan & $\mathrm{XX}$ \\
\hline & Terbilang : & \\
\hline
\end{tabular}

Sumber : Data Diolah

Tabel. 5 Perhitungan Selisih Rencana dan Realisasi Anggaran Biaya

\begin{tabular}{|l|l|l|l|l|}
\hline No. & \multicolumn{1}{|c|}{ Uraian } & $\begin{array}{c}\text { Renacan } \\
\text { Anggaran } \\
\text { yang dibuat } \\
\text { Perusahaan }\end{array}$ & $\begin{array}{c}\text { Realisasi } \\
\text { Anggaran } \\
\text { berdasaran Harga } \\
\text { Bahan Baku }\end{array}$ & Selisih \\
\hline $\mathrm{XX}$ & $\mathrm{XX}$ & $\mathrm{XX}$ & $\mathrm{XX}$ & $\mathrm{XX}$ \\
\hline & & & Jumlah & $\mathrm{XX}$ \\
\hline & & & & \\
\hline
\end{tabular}

Sumber : Data Diolah

\section{Pengujian Hipotesis}

Adapun syarat pengujian hipotesis yang diajukan yaitu :

1.Hipotesis akan diterima, apabila rencana anggaran lebih besar dari realisasi anggaran biaya bahan baku pada proyek rehab gedung PLN Tenggarong tahun 2015.

2. Hipotesis akan ditolak, apabila rencana anggaran lebih kecil dari realisasi anggaran biaya bahan baku pada proyek rehab gedung PLN Tenggarong tahun 2015. 
ANALISIS DAN PEMBAHASAN

Berdasarkan data-data rencana anggaran biaya bahan baku pada bab IV, maka penulis bermaksud meneliti realisasi anggaran biaya bahan baku yang dibutuhkan berdasarkan harga bahan baku tahun 2015 pada proyek rehab gedung PLN Tenggarong pada CV Rajawali Adi Putra.

\section{Realisasi Anggaran Biaya Bahan Baku}

Tabel. 6 Harga Satuan Bahan Baku

\begin{tabular}{|c|l|r|}
\hline \multirow{2}{*}{ NO } & \multicolumn{1}{|c|}{ JENIS BAHAN } & \multicolumn{1}{|c|}{$\begin{array}{c}\text { JUMLAH HARG } \\
\text { (Rp) }\end{array}$} \\
\hline A & Agregat Kasar, Bahan Perekat \& Bahan Jadi & $1.392 .340,00$ \\
\hline B & Bahan Finishing & $482.500,00$ \\
\hline C & Bahan Kayu & $11.466 .500,00$ \\
\hline D & Bahan Lantai, Atap, \& Pelapid Dinding & $75.000,00$ \\
\hline E & Bahan Logam dan Paku & $191.700,00$ \\
\hline F & BahanKunci, Penggantung \& Kaca & $5.919 .000,00$ \\
\hline G & Bahan Listrik & 691.000 \\
\hline & & $\mathbf{2 0 . 2 1 8 . 0 4 0 , 0 0}$ \\
\hline
\end{tabular}

(Sumber : Data Diolah)

Tabel. 7 Analisa Satuan Pekerjaan

\begin{tabular}{|c|l|r|}
\hline NO & \multicolumn{1}{|c|}{ URAIAN PEKERJAAN } & \multicolumn{1}{c|}{$\begin{array}{c}\text { JUMLAH } \\
\text { HARGA (RP) }\end{array}$} \\
\hline I & Pekerjaan Persiapan & - \\
\hline II & Pekerjaan Beton & $243.053,70$ \\
\hline III & Pekerjaan Pasangan & 451.200 \\
\hline IV & Pekerjaan Kusen Pintu dan Jendela & $327.211,00$ \\
\hline V & Pekerjaan Elektrikal Mekanikal & $112.533,50$ \\
\hline VI & Pekerjaan Langit-langit & $100.340,00$ \\
\hline VII & Pekerjaan Finishing & $\mathbf{1 . 2 3 4 . 3 3 8 , 0 3}$ \\
\hline & & JUMLAH \\
\hline
\end{tabular}

(Sumber : Data Diolah) 
Tabel. 8 Realisasi Anggaran Biaya Bahan Baku

\begin{tabular}{|c|c|c|}
\hline NO & URAIAN PEKERJAAN & $\begin{array}{c}\text { JUMLAH } \\
\text { HARGA (Rp) }\end{array}$ \\
\hline I & PEKERJAAN PERSIAPAN & - \\
\hline II & PEKERJAAN PASANGAN & $17.164 .727,84$ \\
\hline III & PEKERJAAN KUSEN PINTU \& JENDELA & $16.608 .760,00$ \\
\hline IV & PEKERJAAN ELEKTRIKAL MEKANIKAL & $7.073 .908,00$ \\
\hline $\mathrm{V}$ & PEKERJAAN LANGIT-LANGIT & $9.428 .410,31$ \\
\hline VI & PEKERJAAN FINISHING & $6.089 .580,64$ \\
\hline VII & PEKERJAAN LAIN-LAIN & $47.574 .570,60$ \\
\hline & JUMLAH TOTAL & 103.993.957,39 \\
\hline
\end{tabular}

(Sumber : Data Diolah)

Tabel. 9 Rekapitulasi

\begin{tabular}{|c|c|c|}
\hline NO & URAIAN PEKERJAAN & $\begin{array}{c}\text { JUMLAH } \\
\text { HARGA (Rp) }\end{array}$ \\
\hline I & PEKERJAAN PERSIAPAN & - \\
\hline II & PEKERJAAN PASANGAN & $17.164 .727,84$ \\
\hline III & PEKERJAAN KUSEN PINTU \& JENDELA & $16.608 .760,00$ \\
\hline IV & PEKERJAAN ELEKTRIKAL MEKANIKAL & $7.073 .908,00$ \\
\hline V & PEKERJAAN LANGIT-LANGIT & $9.428 .410,31$ \\
\hline VI & PEKERJAAN FINISHING & $6.089 .580,64$ \\
\hline VII & PEKERJAAN LAIN-LAIN & $47.574 .570,60$ \\
\hline & JUMLAH TOTAL & 103.993.957,39 \\
\hline & PPN 10\% & 10.399.397,74 \\
\hline & JUMLAH SETELAH PAJAK & 114.939.353,13 \\
\hline & DIBULATKAN & 114.939.000,00 \\
\hline \multicolumn{3}{|c|}{$\begin{array}{c}\text { TERBILANG : "SERATUS EMPAT BELAS JUTA SEMBILAN RATUS } \\
\text { TIGA PULUH SEMBILAN RIBU RUPIAH" }\end{array}$} \\
\hline
\end{tabular}

(Sumber : Data Diolah) 
Tabel. 10 Selisih antara Rencana dengan Realisasi Anggaran Biaya Bahan Baku yang digunakan pada Proyek Rehab Gedung PLN Tenggarong tahun 2015 Pada CV Rajawali Adi Putra

\begin{tabular}{|c|c|c|c|c|}
\hline NO & URAIAN PEKERJAAN & $\begin{array}{c}\text { RENCANA } \\
\text { ANGGARA } \\
\text { N (Dn) }\end{array}$ & $\begin{array}{c}\text { REALISASI } \\
\text { ANGGARA } \\
\text { N (Dn) }\end{array}$ & $\begin{array}{c}\text { SELISI } \\
\mathrm{H}\end{array}$ \\
\hline I & PEKERJAAN PERSIAPAN & - & - & +2 \\
\hline II & PEKERJAAN PASANGAN & 19.011.436,6 & $17.164 .727,8$ & $1.846 .708,8$ \\
\hline III & PEKERJAAN KUSEN PINTU \& & $16.685 .950,0$ & $16.608 .760,0$ & $77.190,00$ \\
\hline IV & PEKERJAAN ELEKTRIKAL & $7.250 .500,0$ & $7.073 .908,0$ & $176.592,00$ \\
\hline $\mathrm{V}$ & PEKERJAAN LANGIT-LANGIT & $9.857 .507,0$ & $9.428 .410,3$ & $429.096,75$ \\
\hline VI & PEKERJAAN FINISHING & $6.519 .694,2$ & $6.089 .580,6$ & $430.113,64$ \\
\hline VII & PEKERJAAN LAIN-LAIN & $47.574 .570,6$ & $47.574 .570,6$ & - \\
\hline & JUMLAH TOTAL & 106.899.658,6 & 103.993.957,3 & 2.959.701,2 \\
\hline & PPN & $10.689 .965,8$ & $10.399397,7$ & $295.970,12$ \\
\hline & JUMLAH SETELAH PAJAK & 117.589.624,4 & 114.939.353,1 & $3.255 .671,3$ \\
\hline & DIBULATKAN & & & 3.255.000,0 \\
\hline
\end{tabular}

\section{Pembahasan Hasil Perhitungan}

Berdasarkan perhitungan harga bahan baku yang digunakan dalam proyek rehab gedung PLN Tenggarong tahun 2015, terdapat selisih antara rencana anggaran biaya bahan baku yang dibuat oleh CV Rajawali Adi Putra dengan realisasi anggaran biaya bahan baku yang digunakan berdasarkan perhitungan harga bahan baku.

Perhitungan harga satuan bahan baku yang dibuat perusahaan pada setiap jenis bahan yang digunakan terdapat selisih dengan realisasi anggaran yang digunakan. Semua rincian harga satuan bahan baku dapat dilihat pada lampiran 1 (satu) dan lampiran 6 (enam). Pada agregat kasar, bahan perekat dan bahan jadi terdapat selisih rencana anggaran dengan realisasi anggaran sebesar Rp.

84.585,00 (delapan puluh empat ribu lima ratus delapan puluh lima rupiah), selisih harga ini terdapat perbedaan harga bahan baku pasir pasang/pasir beton, tanah urug, kerikil, batu gunung, batu bata, semen per zak dan semen per kg (kilogram). Pada bahan finishing terdapat selisih sebesar Rp. 39.940,00 (tiga puluh sembilan ribu sembilan ratus empat puluh rupiah) selisih ini terdapat pada perbedaan harga bahan baku cat interior, cat eksterior, cat dasar dinding, plamir, kertas gosok (amplas), minyak bekisting, lem kayu, dan HPL. Pada jenis bahan kayu terdapat selisih antara rencana anggaran dengan realisasi anggaran sebesar Rp. 631.500,00 (enam ratus tiga puluh satu ribu lima ratus rupiah) selisih ini terdapat pada perbedaan harga bahan baku kayu meranti, plywood $4 \mathrm{~mm}$, plywood 9mm, kayu bekisting dan kayu bengkirai. Pada jenis bahan lantai, atap dan pelapis dinding terdapat selisih antara rencana anggaran dengan realisasi anggaran sebesar Rp. 7.500,00 (tujuh ribu lima ratus rupiah), selisih ini 
terdapat pada perbedaan harga bahan baku gypsum board 9mm. Pada bahan logam dan paku terdapat selisih antara rencana anggaran dengan realisasi anggaran sebesar Rp. 1.300,00 (seribu tiga ratus rupiah), selisih ini terdapat pada perbedaan harga bahan baku besi beton polos/ulir, dan paku sekrup. Pada bahan kunci, penggantung, dan kaca terdapat selisih antara rencana anggaran dengan realisasi anggaran sebesar Rp. 62.250 (enam puluh dua ribu dua ratus lima puluh rupiah), selisih ini terdapat pada perbedaan harga bahan baku semua jenis yaitu kusen alumunium, pasang daun pintu alumunium $80 \mathrm{x}$ $210 \mathrm{~cm}+$ Acessories, dan pasang daun jendela + kaca bening $5 \mathrm{~mm}$ (72 x 125). Pada jenis bahan Listrik terdapat selisih harga antara rencana anggaran dengan realisasi anggaran sebesar Rp. 16.500,00 (enam belas ribu lima ratus rupiah), selisih ini terdapat pada perbedaan harga bahan baku lampu downlight 12 watt, saklar ganda, kabel NYM 3x 2,5 mm2, dan isolasi.

Pada perhitungan analisa satuan pekerjaan berdasarkan Harga Bahan Baku yang dibuat perusahaan dengan yang telah digunakan memiliki selisih keseluruhan sebesar Rp. 148.351,97 (seratus empat puluh delapan ribu tiga ratus lima puluh satu koma sembilan puluh tujuh rupiah) dengan Rincian pada lampiran 3 (tiga) dan lampiran 7 (tujuh). Analisa satuan pekerjaan pada uraian pekerjaan persiapan dan pekerjaan beton tidak memiliki selisih harga, karena pada pekerjaan persiapan dan pekerjaan beton tidak terdapat harga bahan baku yang dibutuhkan, atau selisih sama dengan 0 (nol) dan hanya membutuhkan harga atau biaya tenaga kerja. Analisa satuan pekerjaan pada uraian pekerjaan persiapan terdapat selisih antara rencana anggaran dengan realisasi anggaran sebesar Rp.
128.829,93 (seratus dua puluh delapan ribu delapan ratus dua puluh sembilan koma sembilan puluh tiga rupiah), selisih ini terdapat perbedaan harga bahan baku pada pasangan bata 1:4, plesteran dinding 1:4, acian, benangan, dan dinding lapis HPL. Analisa satuan pekerjaan pada uraian pekerjaan kusen pintu dan jendela terdapat selisih antara rencana anggaran dengan realisasi anggaran sebesar Rp. 300,00 (tiga ratus rupiah), selisih ini terdapat perbedaan harga bahan baku pada biaya kusen profil alumunium. Analisa satuan pekerjaan elektrikal mekanikal terdapat selisih antara rencana anggaran dengan realisasi anggaran sebesar Rp. 7.539,00 (tujuh ribu lima ratus tiga puluh sembilan rupiah), selisih ini terdapat perbedaan harga bahan baku pada pasang instalassi titik lampu, saklar dan stop kontak, dan pasang lampu downlight. Analisa satuan pekerjaan langit-langit terdapat selisih antara rencana anggaran dengan realisasi anggaran sebesar $\mathrm{Rp}$. 4.451,50 (empat ribu empat ratus lima puluh satu koma lima puluh rupiah) selisih ini terdapat perbedaan harga bahan baku rangka langit-langit, dan plafond gypsum board $9 \mathrm{~mm}$. Analisa satuan pekerjaan finishing terdapat selisih antara rencana anggaran dengan realisasi anggaran sebesar $\mathrm{Rp}$. $7.232,40$ (tujuh ribu dua ratus tiga puluh dua koma empat puluh rupiah), selisih ini terdapat perbedaan harga bahan baku pengecatan dinding dalam, palafond dan dinding luar.

Rencana anggaran biaya berdasarkan biaya bahan baku terdapat selisih antara rencana anggaran dengan realisasi anggaran sebesar Rp. 2.959.701,21 (dua juta sembilan ratus lima puluh sembilan ribu tujuh ratus satu koma dua puluh satu rupiah), dengan rincian lengkap pada Lampiran 4 (empat) dan Lampiran 8 (delapan). Pada uraian pekerjaan persiapan tidak 
terdapat selisih antara rencana anggaran dengan realisasi anggaran karena pada pekerjaan ini hanya membutuhkan tenaga kerja. Pada uaraian pekerjaan pasangan terdapat selisish antara rencana anggaran dengan realisasi anggaran sebesar Rp. 1846.708,82 (satu juta delapan ratus empat puluh enam ribu tujuh ratus delapan koma delapan puluh dua rupiah). Pada uraian pekerjaan kusen pintu dan jendela terdapat selisih antara Rencana Anggaran dengan Realisasi Anggaran sebesar Rp. 77.190,00 (tujuh puluh tujuh ribu seratus sembilan puluh rupiah). Pada uraian pekerjaan elektrikal mekanikal terdapat selisih antara rencana anggaran dengan realisasi anggaran sebesar Rp. 176.592,00 (seratus tujuh enam ribu lima ratus sembilan puluh dua rupiah). Pada uraian pekerjaan langit-langit terdapat selisih antara rencana anggaran dengan realisasi anggaran sebesar Rp. 429.096,75 (empat ratus dua puluh sembilan ribu sembilan puluh enam koma tujuh puluh lima rupiah). Pada uraian finishing terdapat selisih antara rencana anggaran dengan realisasi anggaran sebesar Rp. 430.113,64 (empat ratus tiga puluh ribu seratus tiga belas koma enam puluh empat rupiah). Pada uraian pekerjaan lain-lain tidak terdapat selisih antara rencana anggaran dengan realisasi anggaran karena harga yang dibutuhkan dan digunakan tidak terdapat selisih atau selisih sama dengan 0 ( Nol).

Dalam rekapitulasi rencana anggaran biaya dan realisasi anggaran Biaya menunjukan perbedaan harga dengan rincian Lampiran 5 (lima) dan Lampiran 9 (sembilan).

Pada tabel V.5 perhitungan selisih antara rencana anggaran yng dibuat oleh perusahaan dengan anggaran yang dibutuhkan pada proyek rehab gedung PLN Tenggarong, terdapat selisih positif sebesar Rp. 3.255.000,00 (tiga juta dua ratus lima puluh lima ribu rupiah).

Selisih positif yang didapat pada hitungan menunjukan bahwa Perusahaan mendapatkan Keuntungan sebesar Rp. 3.255.000,00 (tiga juta dua ratus lima puluh lima ribu rupiah). Keuntungan positif ini didapat karena adanya perbedaan harga bahan baku yang dibuat oleh perusahaan dengan Realisasi harga atau harga yang dibutuhkan untuk Rehab Gedung PLN Tenggarong.

Adapun perhitungan persentase keuntungan :

Rencana : Rp. 117.589.624,46

dibulatkan Rp. 117.589.000,-

Realisasi : $\quad$ Rp.114.939.353,13

dibulatkan Rp.114.939.000,-

Selisih : Rp. 3.255.000,-

Persentase : $=\frac{3.2 \quad .0}{1.5 \quad .0} \times 100=2,76 \%$

Dengan demikian persentase keuntungan yang didapat CV. Rajawali Adi Putra dalam proyek rehab gedung PLN Tenggarong sebesar $2,76 \%$.

Adapun syarat pengujian hipotesis yang diajukan yaitu :

1. Hipotesis akan diterima, apabila rencana anggaran lebih besar dari realisasi anggaran biaya bahan baku pada proyek rehab gedung PLN Tenggarong tahun 2015.

2. Hipotesis akan ditolak, apabila rencana anggaran lebih kecil dari realisasi anggaran biaya bahan baku pada proyek rehab gedung PLN Tenggarong tahun 2015.

Berdasarkan syarat uji hipotesis tersebut, maka dapat diketahui bahwa rencana anggaran lebih besar dari realisasi anggaran biaya bahan baku pada proyek rehab gedung PLN Tenggarong tahun 2015, sehingga hipotesis yang diajukan dapat diterima.

\section{KESIMPULAN}


Setiap penelitian pasti memiliki pembahasan yang kemudian akan dijadikan sebagai bahan dasar dari hasil penelitian tersebut, dasar penelitian yang biasa disebut sebagai kesimpulan. Berdasarkan hasil penelitian dan hasil analisis data yang dilakukan pada CV. Rajawali Adi Putra mengenai anggaran biaya proyek rehab gedung PLN Tenggarong tahun 2015, maka dapat dikemukakan kesimpulan dan saran sebagai berikut :

1. Dalam proyek rehab gedung PLN Tenggarong tahun 2015 pada CV. Rajawali Adi Putra terdapat selisih antara rencana dengan realisasi anggaran biaya bahan baku, selisih anggaran

\section{DAFTAR PUSTAKA}

Andriana, Permodalan Anggaran Dengan Microsoft Excel, 2008, PT Elex Media Komputindo, Jakarta.

Ervianto, I. Wulfram, Manajemen Proyek dan Konstruksi, 2005, Edisi Revisi Penerbit Andi, Yogyakarta.

Gray, F. Clifford, dan Erik W. Larson, Manajemen Proyek Proses Manajerial, 2006, Terjemahan, Dwi Prabantini, Penerbit Andi, Yogyakarta.

Haruman, Tendi dan Sri Rahayu, Penyususnan Anggaran Biaya, 2007, Graha Ilmu, Yogyakarta.

Malik, Alfian, Pengantar Bisnis Jasa Pelaksana Konstruksi, 2010, Penerbit Andi, Jakarta.

Moeljadi, Manajemen Keuangan, 2006, Penerbit Banyu Media Publishing, Malang.

Rudianto, Akuntansi Manajemen Informasi Untuk Pengambilan Keputusan

Manajemen, 2006,Penerbit Grasindo, Jakarta.

Rudianto, Penganggaran, 2009,

Penerbit Erlangga, Jakarta.

Sirait, Justine, Anggaran Sebagai Alat

Bantu Manajemen, 2006, Grasindo, Jakarta. sebesar Rp. 3.255.000,00 (tiga juta dua ratus lima puluh lima ribu rupiah) dengan adanya selisih biaya bahan baku maka perusahaan mendapatkan keuntungan, karena perusahaan dapat menggunakan bahan baku secara efisien.

2. Jadi kesimpulannya adalah benar terdapat selisih anggaran antara rencana dengan realisasi anggaran biaya bahan baku dalam proyek rehab gedung PLN Tenggarong tahun 2015 pada CV Rajawali Adi Putra, sehingga hipotesis yang diajukan dapat diterima.

Solihin, Ismail, Pengantar Manajemen, 2009, Penerbit Erlangga, Jakarta. Sugiono, Arif, Manajemen Keuangan Untuk Praktisi Keuangan, 2009, Penerbit Grasindo, Jakarta.

Sukoco, Badri Munir, Manajemen Administrasi Perkantoran Modern, 2007, Erlangga, Jakarta.

Susanta, Gatut, Renovasi Rumah, 2008, Penerbit Swadaya, Jakarta

Susanta, Gatut, Menghitung Anggaran Membangun Rumah, 2013, Penerbit Griya Kreasi, Jakarta.

Syah, Mahendra Sultan, Manajemen Proyek (Kiat Sukses Mengelola Proyek), 2004, PT Gramedia, Jakarta.

Usman Husaini, Manajemen Teori, Praktik, dan Riset Pendidikan, 2008, PT Bumi Aksara, Jakarta Timur. 